\title{
ESTUDIO ANATOMICO DE HIPPOCRATEA EXCELSA HBK. (HIPPOCRATEACEAE)
}

\author{
Marcelina Graciela Villa Fernandez \\ Josefina Barajas-Morales \\ Instituto de Biología \\ Universidad Nacional Autónoma de México \\ Apartado postal $70-233$ \\ 04510 México, D.F. \\ Y

\section{Guillermo Angeles} \\ Estación de Biología Tropical "Los Tuxtlas" \\ Universidad Nacional Autónoma de México \\ Apartado postal 94 \\ 95700 San Andrés Tuxtla, Veracruz
}

\begin{abstract}
RESUMEN
Se presenta una descripción anatómica de hoja, xilema secundario y corteza del tallo y de la raíz de Hippocratea excelsa HBK. La corteza de esta especie, conocida popularmente como "cancerina", es usada de manera tradicional para el tratamiento de diferentes enfermedades; además se obtienen de ella compuestos de importancia económica como la "guttapercha". La hoja tiene estomas del tipo actinocítico, el parénquima en empalizada contiene abundantes espacios intercelulares, en las células epidérmicas se encuentran drusas y abundantes taninos. El xilema secundario del tallo y de la raíz presenta porosidad difusa, vasos solitarios, parénquima paratraqueal escaso y apotraqueal difuso en agregados, y radios multiseriados. En el parénquima del xilema secundario de la raíz se observan almidones y otros compuestos no identificados. La corteza de la raíz contiene abundantes taninos, cristales solitarios y fibras de dos formas diferentes: unas puntiagudas y otras con puntas romas.
\end{abstract}

\begin{abstract}
An anatomical description for the leaf, secondary xylem and bark of stem and root of Hippocratea excelsa HBK. is presented. The bark of this species, popularly known as "cancerina" is traditionally used in the treatment of different diseases. Economically important compounds (e.g. guttapercha) are also obtained from the bark. The leaf has stomata of actinocytic type, its palisade parenchyma contains an abundance of intercellular spaces, and tannins and druses are found in the epidermic cells. Secondary xylem of stem and root presents diffuse porosity, solitary vessels, scanty paratracheal and diffuse-in aggregates apotracheal parenchyma, and multiseriate rays. Starch and other non identified compounds were observed in the secondary xylem parenchyma of the root. The root bark has abundant tannins, solitary crystals and fibers of two different forms: some with spindle-shaped and some others with blunt ends.
\end{abstract}




\section{INTRODUCCION}

La familia Hippocrateaceae está integrada por más de 300 especies, distribuidas principalmente en las regiones tropicales de ambos hemisferios (Dodson y Robyns, 1965), que en su mayoría están contenidas en dos géneros: Hippocratea con alrededor de 100 especies y Salacia con 200 aproximadamente. Excepto por el trabajo realizado por Mennega (1972), los miembros del género Hippocratea han sido poco estudiados desde el punto de vista anatómico; la mayor cantidad de información existente es de tipo florístico o etnobotánico, con énfasis en el uso de la corteza para fines medicinales.

En México, Hippocratea excelsa es llamada popularmente mata piojo, miseg-bat (Oaxaca), barajillo (Guerrero), piojo, zipche (Chiapas) y palo de reguilete (Yucatán). En medicina tradicional se le conoce como cancerina y ha sido principalmente utilizada para el tratamiento de enfermedades como las úlceras gástricas, los padecimientos renales, las afecciones de la piel, la amenorrea y algunas infecciones uterinas. Debido principalmente a sus propiedades aparentemente curativas, la especie ha sido objeto de una sobreexplotación que, creemos, podría llevarla a la extinción. Por otra parte, López (1989) obtuvo de la corteza de esta planta el trans poliisopreno llamado comúnmente "guttapercha", que es un polímero semejante al caucho pero que es más maleable y con mayor resistencia que éste.

En un estudio morfológico de las especies americanas de Hippocrateaceae, Smith (1940) observó diferencias en la posición del disco estaminal de tres especies del género Hippocratea, en $H$. volubilis el ovario se halla inmerso en el disco estaminal, en $H$. celastroides el disco está debajo del ovario y en $H$. excelsa se encuentra semiinmerso. Apoyado en dichas diferencias, el mismo autor asignó los nombres de Pristimera celastroides y Hemiangium excelsum a las dos últimas especies. Más tarde, Metcalfe y Chalk (1957) recopilaron información anatómica para la familia, apegándose a la nomenclatura asignada por Smith. En 1965 Dodson y Robyns describieron la presencia de floema incluido en el tallo de algunas especies y mantuvieron a Hippocratea y Hemiangium como géneros diferentes.

Utilizando como base estos estudios, Mennega (1972) estableció una comparación anatómica de las especies que integran las Hippocrateaceae señalando la presencia de floema incluido como una caracterísitica notable pero sin significancia en la posición sistemática de los géneros. Sin embargo, indicó que la altura y ancho de los radios y la presencia de fibras septadas son caracteres importantes para separar la familia en dos grupos, por lo que mantuvo los géneros reconocidos por Smith y consideró a Hippocratea como diferente de Hemiangium. No obstante, en fecha posterior Cronquist (1981) reunió información anatómica general sobre la familia y reconoció el género Hippocratea en sentido amplio sin considerar a Hemiangium. Entre los botánicos de América parece no haber un consenso acerca de la existencia de los dos géneros y más bien la mayoría considera a todo el conjunto como Hippocratea (R. M. Fonseca com. pers.).

Debido a los problemas de situación taxónomica de $H$. excelsa y a la gran cantidad de propiedades medicinales e industriales, que le son atribuidas, se consideró de utilidad realizar el estudio anatómico de las partes vegetativas de la planta. El trabajo comprende la descripción anatómica de la hoja, el tallo y la raíz, incluyendo tanto el xilema como la corteza de dichos órganos. 
Esperamos que esta contribución al conocimiento de la anatomía de $H$. excelsa apoye trabajos posteriores para lograr su adecuada ubicación genérica y un mejor entendimiento de la familia Hippocrateaceae.

\section{MATERIAL Y METODO}

El ejemplar estudiado se colectó cerca de la laguna de Nuzco, en el ejido El Veinte, municipio de Tecpan de Galeana, en el estado de Guerrero, cuya localización geográfica es la siguiente: 17012'00" longitud oeste y 10047’30" latitud norte. Se eligió un individuo sano, maduro y muy ramificado del que se tomó una muestra de tallo y de raíz de aproximadamente $25 \mathrm{~cm}$ de longitud.

Para realizar las observaciones y mediciones de las células completas se disociaron los tejidos de madera y corteza en solución de Jeffrey (Johansen, 1940). El estudio de la corteza se efectuó tomando dos bloques de $5 \mathrm{~cm}$ de lado que se fijaron en FAA [formol (10 cc), alcohol (50 cc), ácido acético (5 cc) y agua (35 cc)], se lavaron con agua y se deshidrataron en alcoholes graduales (50\%, 70\%, $80 \%, 96 \%$ y $100 \%)$, se aclararon en xilol y fueron incluidos en parafina histológica, de acuerdo con la técnica de Sass (1961). Los bloques así tratados fueron cortados en secciones microscópicas de 10 a $15 \mu \mathrm{m}$ de grosor y se rehidrataron para teñirlos con safranina-verde rápido o azul de toluidina (Johansen, 1940). Los cortes ya coloreados se deshidrataron con alcoholes graduales, se aclararon en xilol y se montaron en resina sintética obteniéndose varias laminillas fijas para hacer observaciones microscópicas.

La descripción de las características macroscópicas y microscópicas de la madera de tallo y raíz, se realizó de acuerdo con los estándares y definiciones de Chattaway (1932) y de IAWA (1964, 1989).

\section{RESULTADOS}

I. Hoja

Se describe una sección transversal de la hoja comprendiendo la parte lateral y la nervadura central.

A) Parte lateral (Lám. 1, Figs. A-D)

Epidermis del haz (Ep). Monoestratificada, de células isodiamétricas que en su interior contienen cristales en forma de drusas; con una cutícula delgada bien diferenciada.

Hipodermis. Monoestratificada en algunas regiones y pluriestratificada en otras.

Parénquima en empalizada $(\mathrm{Pe})$. Pluriestratificado, que al ser teñido con safraninaverde rápido, deja ver evidentes espacios sin colorear, además de inclusiones abundantes que se tiñen de color obscuro.

Parénquima esponjoso (Ps). En él se encuentran inmersos pequeños haces vasculares menores, delimitados por fibras y/o esclereidas. 

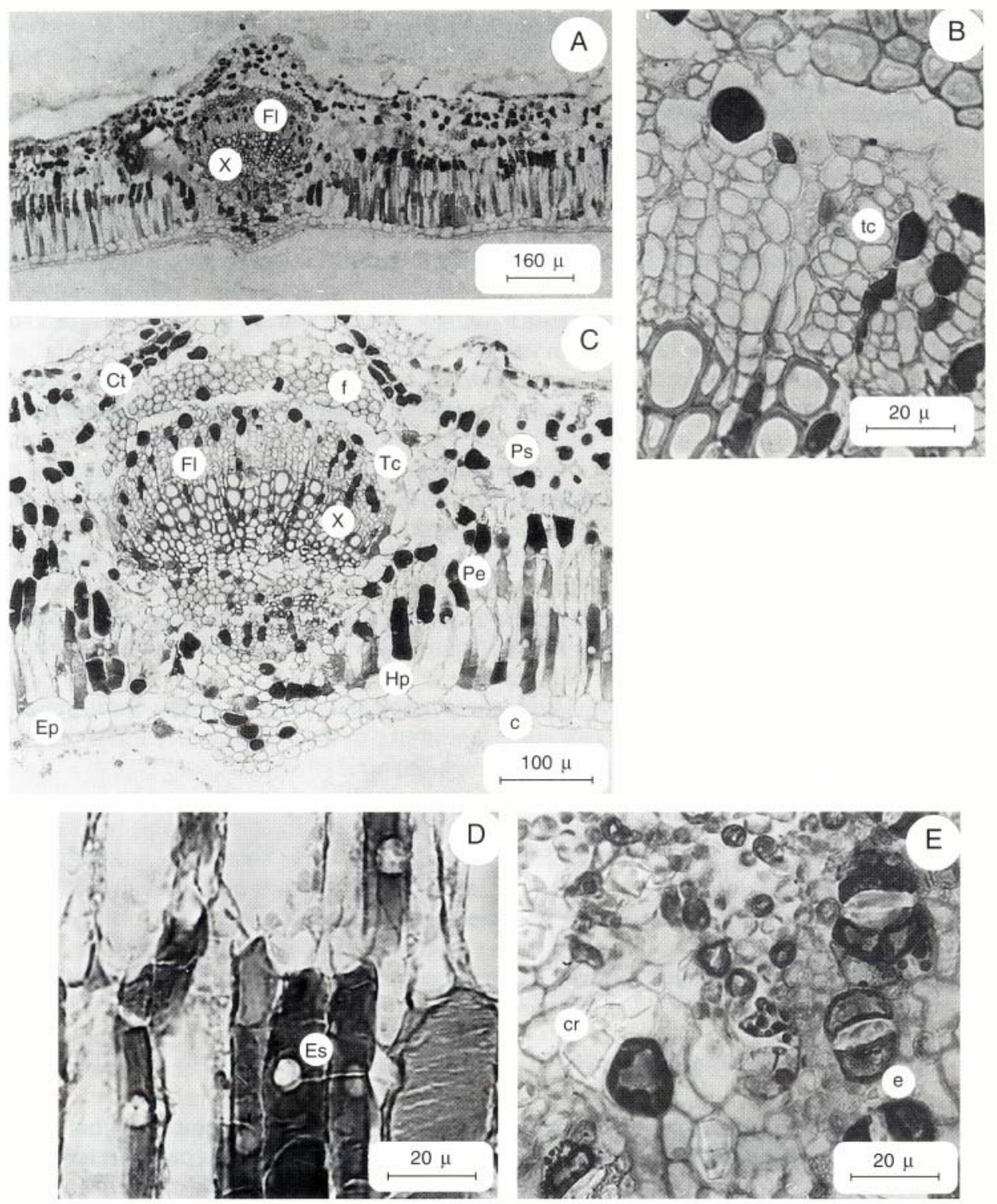

Lám. 1. Corte transversal de la hoja. Fig. A. Xilema (X) y floema (FI). Fig. B. Tubos cribosos (tc) del floema funcional. Fig. C. Cutícula (c), parénquima en empalizada $(\mathrm{Pe})$, parénquima esponjoso ( $\mathrm{Ps}$ ), xilema $(x)$, tubo criboso $(T c)$, fibras $(f)$, floema $(F I)$, células taniníferas $(C t)$ y epidermis (Ep). Fig. D. Espacios vacíos en el parénquima en empalizada (Es). Fig. E. Corte sagital de la hoja, presencia de estomas (e) y cristales (Cr). 
Epidermis del envés. Monoestratificada, formada por células de diferentes formas geométricas, alargadas y poliédricas, predominando estas últimas. Los estomas encontrados son de tipo actinocítico (Esau, 1976), con el ostiolo rodeado por más de tres células acompañantes (subsidiarias) alargadas y con su eje mayor perpendicular al ostiolo.

B) Nervadura central (Lám. 1, Figs. A, B y C)

Epidermis del haz. Monoestratificada, con una cutícula (c) delgada bien definida. Hipodermis ( $\mathrm{Hp}$ ). En algunas áreas es monoestratificada y en otras pluriestratificada, con células isodiamétricas.

Parénquima $(P)$. Formado por células de forma irregular que se distribuyen radialmente y que contienen abundantes taninos y drusas. Entre las células parenquimáticas se hallan algunos paquetes de fibras (f).

Xilema $(X)$. Presenta una disposición radial posterior al parénquima; en él se evidencian paquetes de fibras $\mathrm{y} / \mathrm{o}$ esclereidas.

Floema (FI). Inmerso dentro del parénquima, muy escaso o poco evidente con la tinción empleada.

Parénquima. De células isodiamétricas y abundantes taninos.

Hipodermis. Monoestratificada.

Epidermis del envés. Monoestratificada.

\section{Tallo}

\section{A) Xilema secundario}

Características macroscópicas

La albura y el duramen son de color blanco uniforme a ligeramente amarillento, sin olor ni sabor, de lustre y textura mediana; el grano es entrecruzado y la dureza mediana, con 0.64 de gravedad específica; los anillos de crecimiento son inconspicuos y con la ayuda de una lupa se aprecian abundantes poros y radios.

Características microscópicas (Lám. 2, Figs. A-D)

Vasos. Porosidad difusa con poros ovalados principalmente solitarios, numerosos $\left(35 / \mathrm{mm}^{2}\right)$, con diámetro tangencial de $131 \mu \mathrm{m}$ en promedio; los elementos de vaso son medianos con longitud promedio de $656 \mu \mathrm{m}$ (423-902 $\mu \mathrm{m})$; platina de perforación simple con inclinación de $60^{\circ}$, punteaduras intervasculares y de vaso a radio alternas, de 4 a $5 \mu \mathrm{m}$ de diámetro.

Parénquima axial. Paratraqueal escaso y apotraqueal en agregados, abundante.

Parénquima radial. Los radios son escasos $(4 / \mathrm{mm})$, heterocelulares, principalmente multiseriados, con 14 hileras de células procumbentes y un número muy variable de células marginales erectas; son moderadamente altos, con altura promedio de $3833 \mu \mathrm{m}$ y contienen cristales prismáticos de oxalato de calcio. 

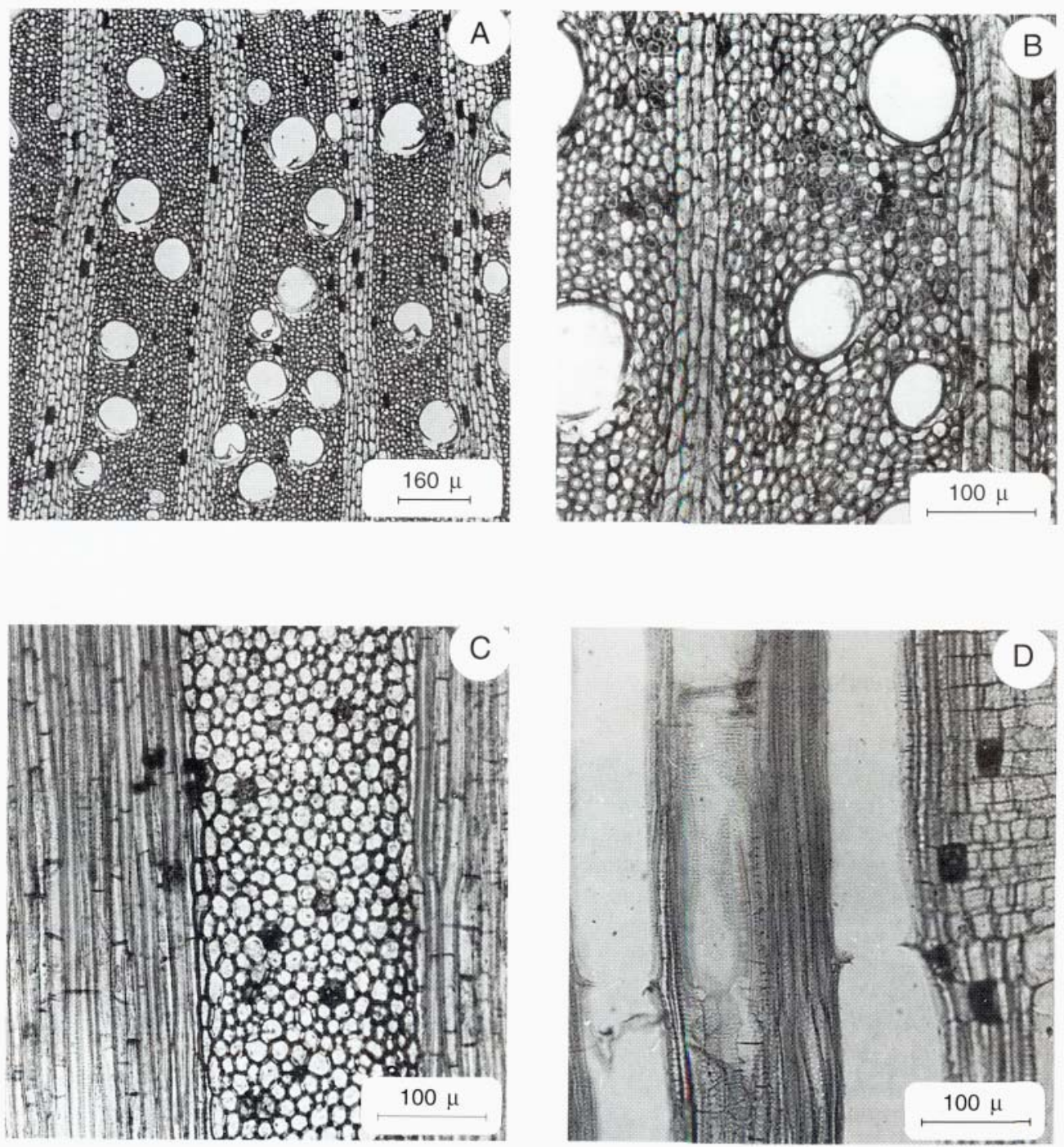

Lám. 2. Xilema secundario del tallo. Fig. A. Sección transversal: porosidad difusa y células taniníferas en los radios. Fig. B. Parénquima apotraqueal en agregados y radios multiseriados. Fig. C. Sección tangencial: radios heterocelulares, células procumbentes, parénquima axial abundante. Fig. D. Sección radial: elementos de vaso, platina de perforación simple y células taniníferas radiales. 
Fibras. De tipo fibrotraqueidas, medianas, con longitud promedio de $1507 \mu \mathrm{m}$ (1034$2209 \mu \mathrm{m})$, de pared gruesa, de $7 \mu \mathrm{m}$ de espesor y $21 \mu \mathrm{m}$ de diámetro tangencial.

Otras características. Anillos de crecimiento inconspicuos, delimitados por parénquima marginal y presencia de máculas medulares.

B) Corteza

La corteza se considera aquí siguiendo los criterios de Roth (1969) y Trockenbrodt (1990) como el conjunto de tejidos externos al cambium vascular.

Características macroscópicas

La corteza es fisurada a ligeramente escamosa, de color gris verdoso; se diferencia en externa e interna y mide $5 \mathrm{~mm}$ de grosor total; presenta lenticelas con abertura vertical, distribuidas en bandas o hileras horizontales; con un sabor ligeramente picante; sin olor; de textura granulosa. La corteza interna es de color café rojizo muy claro y le corresponden $2 \mathrm{~mm}$ de grosor.

Características microscópicas (Lám. 3, Figs. A-D)

La corteza está integrada por floema y peridermis.

Floema (FI). Está formado por diferentes tipos de células: elementos cribosos que tienen un diámetro tangencial promedio de $26 \mu \mathrm{m}$, células acompañantes, células de parénquima axial, parénquima tanífero y parénquima cristalífero (con cristales grandes, solitarios, prismáticos y abundantes). Presenta numerosos paquetes de esclereidas (Es) y escasas fibras.

Los radios (cr) tienen un grosor total de $1640 \mu \mathrm{m}$ y conservan la misma anchura que en la madera, o se hacen ligeramente más anchos. En este último caso, el aumento de tamaño está dado por un incremento en el diámetro tangencial de las células, lo que las hace simular células cuadradas de pared delgada (en sección transversal); también se observan células con cristales, paquetes de esclereidas (Es) y células taníferas muy alargadas tangencialmente.

Peridermis ( $p)$. Es un tejido normalmente formado por tres zonas: la felodermis, el felógeno y el felema. En la especie aquí descrita se aprecian cinco peridermis sucesivas. En la siguiente descripción sólo se hace referencia a la organización de la primera peridermis.

El felógeno no está bien delimitado en los cortes obtenidos.

La felodermis (Fed) es un tejido vivo de origen secundario que se desarrolla de manera centrípeta a partir del felógeno, formando parte de la peridermis y semejando al parénquima cortical (Junikka, 1994). Este tejido se presenta como una zona externa al córtex y está integrado por dos hileras de células parenquimáticas.

El felema (fel) está constitutido por células rectangulares aparentemente vacías, de pared delgada, muy homogéneas en su disposición, arregladas en hileras de 12-15 células, con una longitud radial de $624 \mu \mathrm{m}$ en promedio para la primera peridermis. 

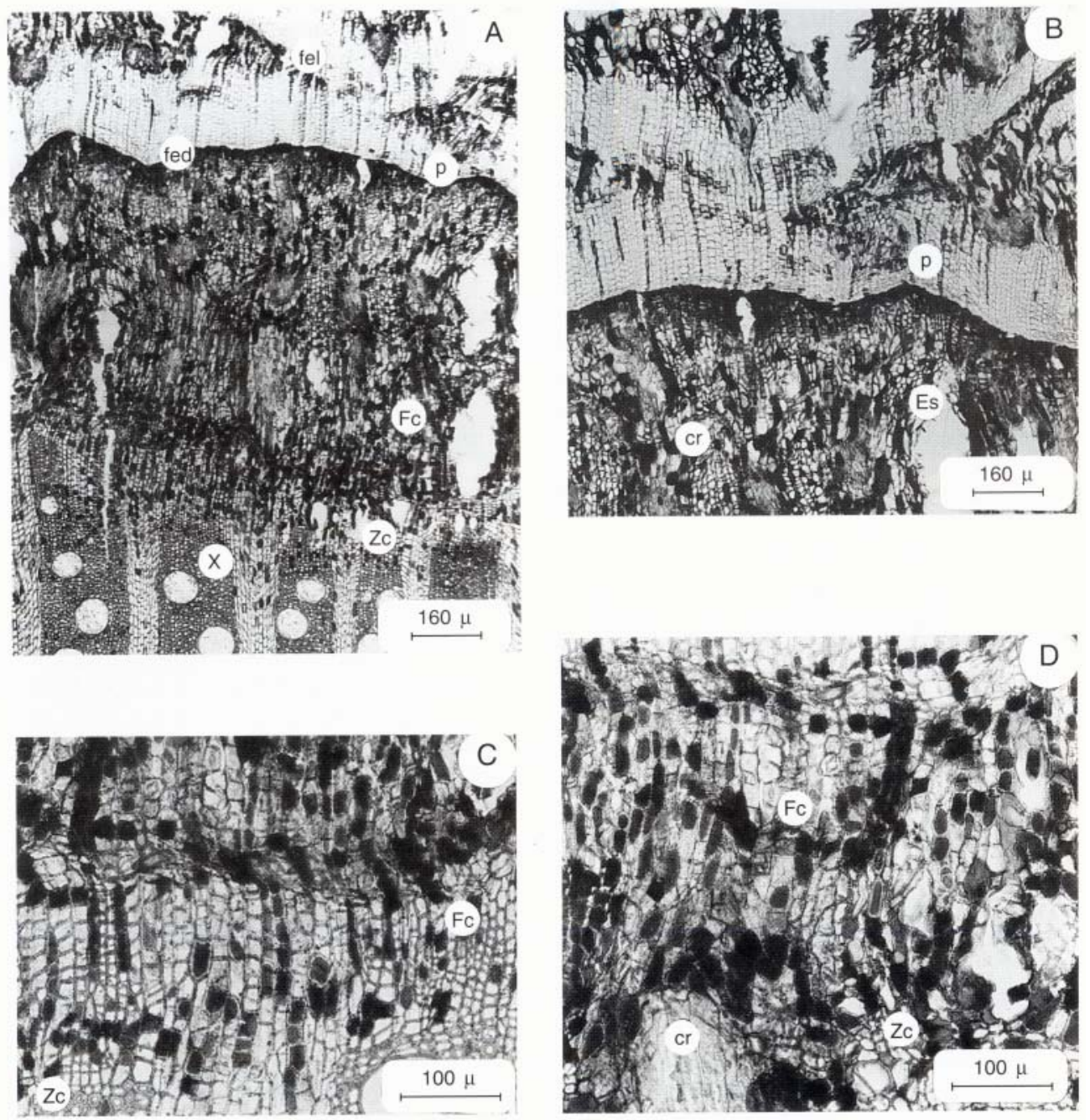

Lám. 3. Corteza del tallo en sección transversal. Fig. A. Xilema (x), zona cambial (Zc) con células ordenadas en hileras posteriores al xilema, floema conductor $(F c)$, peridermis $(p)$, felodermis (fed), felema (fel). Fig. B. Células radiales (cr), espacios de paquetes de esclereidas (Es) y peridermis ( $p$ ). Fig. C. Zona cambial $(\mathrm{Zc})$ y floema conductor $(\mathrm{Fc})$. Fig. D. Células radiales (cr), floema conductor (Fc) y zona cambial $(\mathrm{Zc})$. 
III. Raíz

El sistema radical es pivotante o típico y presenta crecimiento secundario.

A) Xilema secundario

Características macroscópicas

Madera de color café claro homogéneo en la que no se observa diferencia entre el duramen y la albura, sin olor ni sabor, poco lustrosa, con una textura que va de mediana a fina, grano irregular a entrecruzado; de dureza mediana y 0.67 de gravedad específica. Los anillos de crecimiento no se aprecian a simple vista y con la ayuda de una lupa se distinguen poros y radios abundantes, estos últimos evidentes sin lente de aumento, debido a su color blanquecino.

Características microscópicas (Lám. 4, Figs. A-D)

Vasos. Porosidad difusa, con poros ovalados, principalmente solitarios, numerosos $\left(54 / \mathrm{mm}^{2}\right)$ y pequeños, con un diámetro tangencial de $97 \mu \mathrm{m}$ en promedio; los elementos de vaso son medianos, con longitud promedio de $613 \mu \mathrm{m}(489-1194 \mu \mathrm{m})$, con platina de perforación simple y una inclinación de $70^{\circ}$; punteaduras intervasculares y de vaso a radio alternas, de 4-5 $\mu \mathrm{m}$ de diámetro; presentan gomas o resinas.

Parénquima axial. Paratraqueal escaso, vasicéntrico y apotraqueal en agregados, medianamente abundante.

Parénquima radial. Con pocos radios $(4 / \mathrm{mm})$, éstos heterocelulares, principalmente multiseriados, formados de células procumbentes en el cuerpo y una o varias hileras de células erectas en los márgenes; son moderadamente altos, con $5653 \mu \mathrm{m}$ de altura en promedio. También se observan abundantes taninos.

Fibras. De tipo fibrotraqueidas, muy cortas, con longitud promedio de $668 \mu \mathrm{m}$ (968$1833 \mu \mathrm{m})$, con pared delgada de $5 \mu \mathrm{m}$ de espesor y $17 \mu \mathrm{m}$ de diámetro tangencial.

Otras características. Los anillos de crecimiento son inconspicuos, delimitados por fibras de pared gruesa o parénquima, observándose máculas medulares muy evidentes.

B) Corteza

Características macroscópicas

La corteza es de color café rojizo o rosáceo, con abundantes manchas grisáceas, sin olor, con sabor ligeramente astringente y textura ligeramente fibrosa. El grosor total es de $5 \mathrm{~mm}$.

Características microscópicas (Lám. 5, Fig. A)

En sección transversal se puede observar desde el cambium vascular hasta el exterior del tronco, la siguiente distribución de tejidos: floema secundario, córtex y peridermis, esta última integrada a su vez por felodermis, felógeno y felema. 
Acta Botánica Mexicana (1998), 43:7-21
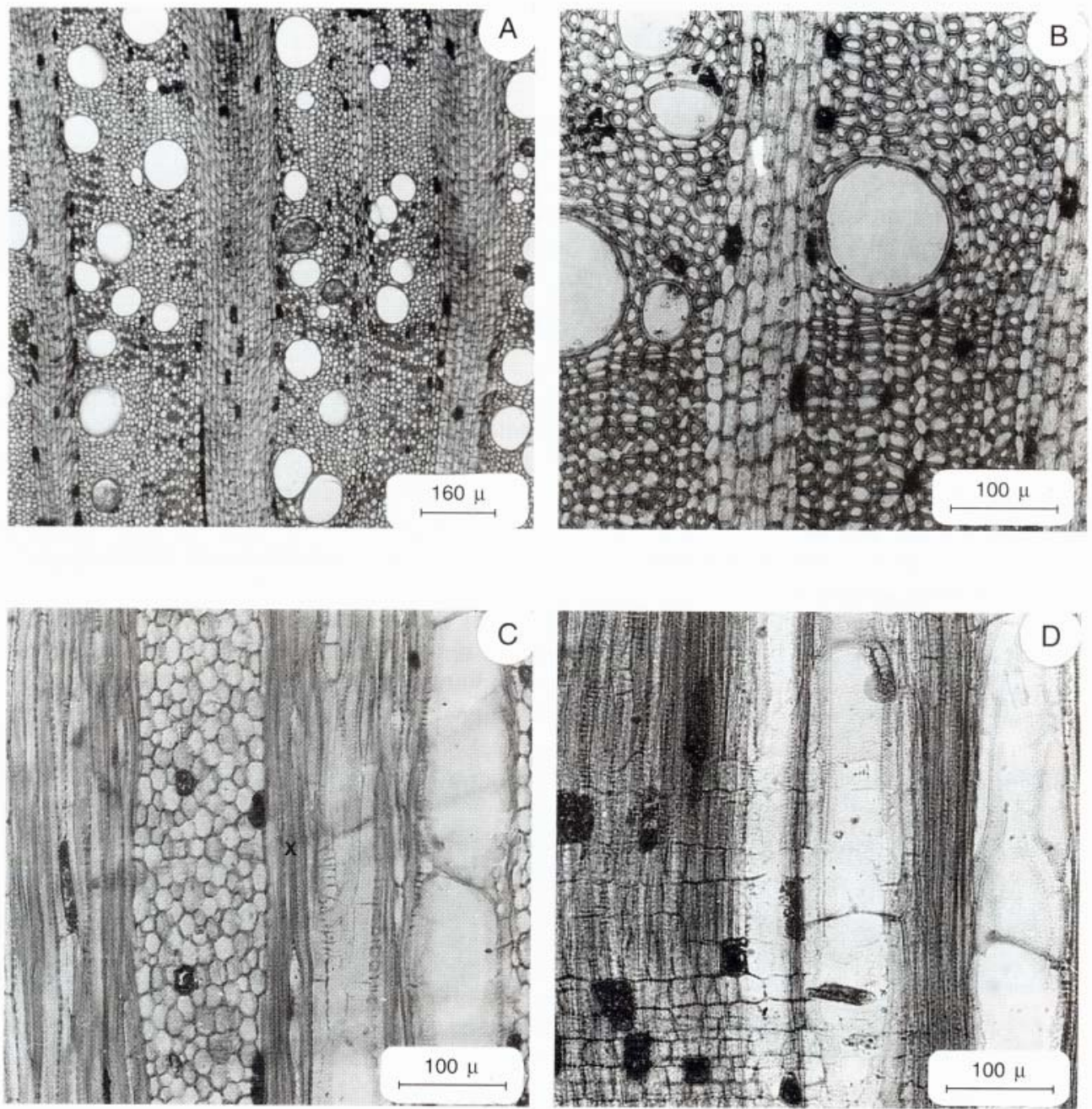

Lám. 4. Xilema secundario de la raíz. Fig. A. Sección transversal: porosidad difusa y células radiales. Fig. B. Parénquima apotraqueal en agregados y paratraqueal escaso vasicéntrico. Fig. C. Sección tangencial: radios heterogéneos y parénquima axial. Fig. D. Sección radial: elemento de vaso, platina de perforacion simple y células taniníferas radiales. 
Floema secundario (Fig. B). Tiene una amplitud radial total de $1710 \mu \mathrm{m}$ y se encuentra integrado por dos áreas organizadas a manera de triángulos complementarios, una incluye a los elementos axiales y la otra a los radiales. Los elementos axiales se encuentran en los triángulos cuyas bases están cercanas al cambium y sus ápices dirigidos hacia el córtex. Los tipos celulares que se observan en él son: tubos cribosos de forma isodiamétrica en vista transversal y $12 \mu \mathrm{m}$ de diámetro tangencial, células acompañantes de forma irregular, dos por cada tubo criboso, evidentes sólo en algunos casos. El parénquima radial (te), también llamado "tejido de expansión", está distribuido por todo el floema y forma las otras áreas triangulares cuyas bases, hasta de 8 células cada una, se hallan cerca del córtex y con sus ápices dirigidos hacia la madera; las células radiales en la base de los triángulos son esféricas y las de los ápices (cr) se observan con forma cúbica, encontrándose entre ellas algunas esclereidas dispersas.

Las fibras son de dos tipos: unas de pared gruesa (E), escasas, con longitud promedio de $784 \mu \mathrm{m}(93-145 \mu \mathrm{m})$ y otras de paredes sumamente delgadas $(F)$, de extremos romos, muy abundantes, con contenidos no identificados en su interior, con longitud promedio de $935 \mu \mathrm{m}$ (97-192 $\mu \mathrm{m})$.

Córtex. Area que mide $1063 \mu \mathrm{m}$ en dirección radial y está constituida por varias capas de células alargadas tangencialmente, ordenadas en hileras y con algunos grupos de células colapsadas. En este tejido se observan células parenquimáticas taníferas de forma muy alargada tangencialmente; también se presentan cristales en gran abundancia, almidón y paquetes de esclereidas.

Peridermis (Lám. A y C). Area inmediatamente externa al floema con amplitud radial total de $1067 \mu \mathrm{m}$. formada por la felodermis, el felógeno y el felema. La primera peridermis está organizada de la siguiente manera:

Felodermis (fed). Zona externa al córtex. En ella se observa una franja de células cuadradas muy regulares, ordenadas en hileras radiales de tres, en algunas de ellas se aprecian taninos y/o abundantes cristales solitarios o agrupados; se presentan también esclereidas de tamaños variados.

Felógeno (fe). Zona externa a la felodermis en la que se encuentra una hilera de células rectangulares.

Felema (fel). Zona exterior al felógeno, formada por varias capas de células cuadradas muy homogéneas, de apariencia vacía y paredes delgadas.

\section{DISCUSION Y CONCLUSIONES}

Metcalfe y Chalk (1957), en su descripción de la familia Hippocrateaceae y refiriéndose a la hoja, mencionan que ésta posee un mesófilo céntrico, además de una hipodermis con localización isobilateral, igual a la que encontramos en el ejemplar estudiado de Hippocratea excelsa; con respecto a los estomas, señalan que son de tipo anemocítico en todos los géneros de la familia, sin embargo en la planta motivo de este trabajo fueron de tipo actinocítico. Los mismos autores mencionan la presencia de abundantes taninos y cristales, lo que también se observó en el individuo estudiado, además de numerosas drusas en la epidermis. No se pudo comprobar la existencia de los canales de látex que menciona Cronquist (1981) en la descripción de la familia. 

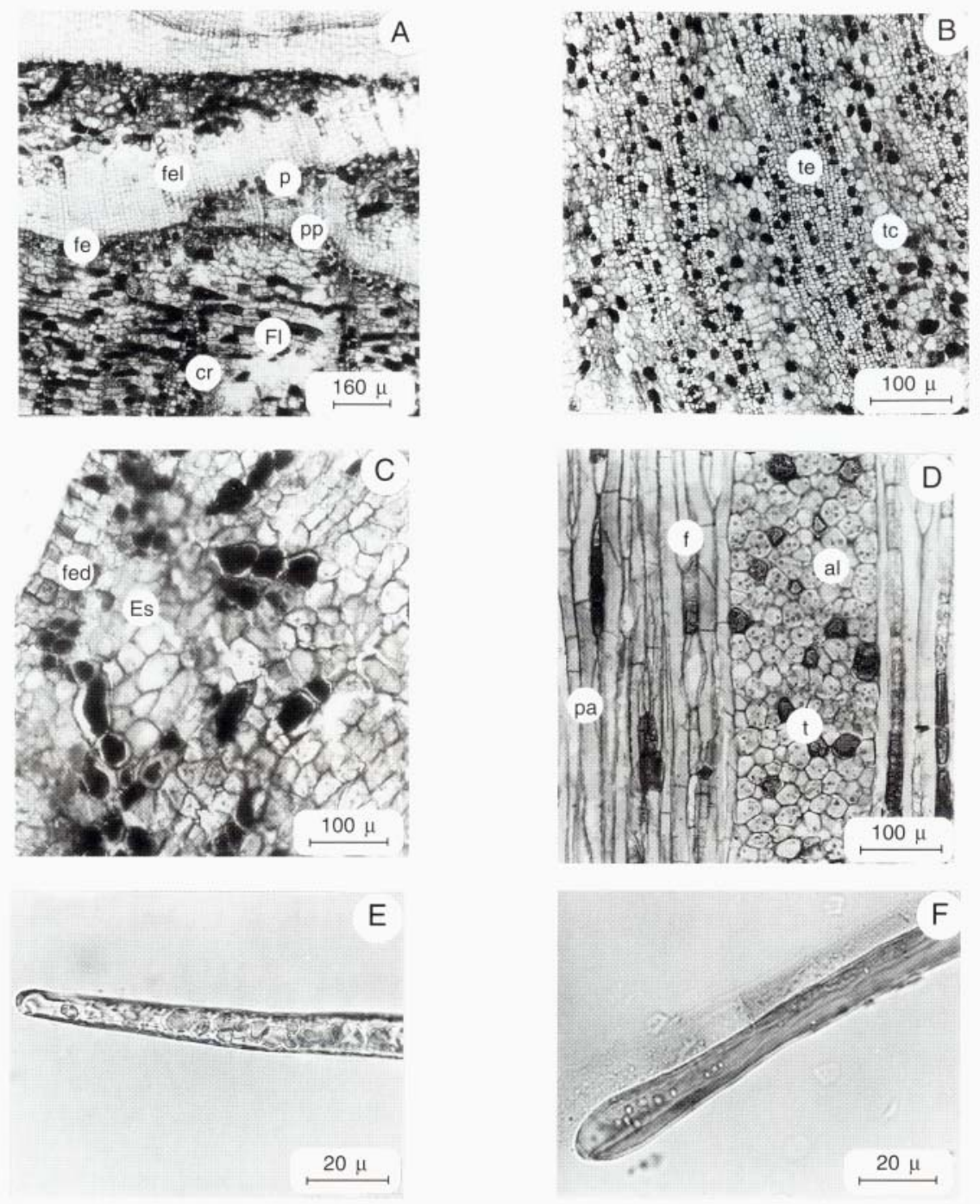

Lám. 5. Corteza de la raíz. Fig. A. Sección transversal: floema (FI), radios (cr), primera peridermis (pp) y las subsiguientes peridermis (p), felógeno (fe) y felema (fel). Fig. B. Tejido de expansión (te), floema con taninos, tubos cribosos (tc). Fig. C. Felodermis (fed), paquetes de esclereidas (Es) y células con contenidos. Fig. D. Corte tangencial: células radiales con taninos ( $\mathrm{t}$ ) y con almidón (al), parénquima axial (pa), fibras de extremos romos (f). Fig. E. Material disociado: fibras de extremos agudos, pared gruesa y abundantes contenidos. Fig. F. Fibras de extremos romos, pared delgada y escasos contenidos. 
Con respecto a las características macroscópicas de la madera del tallo y de la raíz, no se observaron diferencias significativas entre ambas, pero en cuanto a las microscópicas se notaron algunas divergencias importantes: los elementos de vaso del tallo son de mayor diámetro que los de la raíz, coincidiendo con lo observado por Patel (1965); el parénquima axial en el tallo es de tipo paratraqueal vasicéntrico y apotraqueal en agregados medianamente abundante, muy similar al mencionado por Mennega (1972) para la familia Hippocrateaceae. En la raíz el parénquima es paratraqueal vasicéntrico escaso y apotraqueal en agregados, básicamente del mismo tipo que en el tallo, aunque en general el parénquima parece más abundante en la raíz, lo que coincide con lo señalado por Cronquist (1981) y Dodson y Robyns (1965) para la familia Hippocrateaceae.

Los radios son mucho más anchos en el tallo que en la raíz, hecho que está totalmente de acuerdo con lo observado por Mennega (1972) en su trabajo relativo a la familia Hippocrateaceae, en el que encontró radios muy anchos en varios de los géneros e incluso en varias especies de Hippocratea. Contrario a estos hallazgos, Patel (1965) en su estudio comparativo del xilema secundario en tallos y raíces, menciona que los radios son más angostos, el parénquima es más abundante y las fibras son de mayor diámetro en el tallo que en la raíz, aunque es factible explicar estas diferencias en función del carácter más general de la investigación realizada por este autor, quien trabajó con diferentes géneros de Angiospermas.

Otra discrepancia digna de mención consiste en que en la madera de la raíz se hallan abundantes máculas medulares que no fueron observadas en el tallo. Según Panshin y De Zeeuw (1970), las máculas medulares presentes en esta última son resultado de daños en el cambium producidos por larvas de insectos. En el caso de la raíz no existen referencias al respecto, por lo que en el ejemplar estudiado el daño a la misma puede atribuirse a los diferentes organismos que habitan en el suelo. También se produce daño a la raíz cuando se extrae la llamada "cancerina", que consiste en el desprendimiento total de la corteza; éste proceso se realiza de manera mecánica por las personas dedicadas a la recoleccción de plantas medicinales.

Comparándola con otras especies del mismo género, la madera del tallo y de la raíz de $H$. excelsa presenta punteaduras intervasculares alternas y no areoladas y fibras exclusivamente del tipo de fibrotraqueidas, características que difieren notablemente de lo encontrado en los demás representantes estudiados de Hippocratea (Mennega, 1972). También Metcalfe y Chalk (1957) señalan la existencia de canales de látex y corcho muy desarrollado para algunos géneros de la familia, mismos que en este caso no fueron encontrados.

Con respecto a la corteza del tallo y de la raíz, se encontraron diferencias macroscópicas y microscópicas evidentes; entre las primeras sobresalen: el color café obscuro en el tallo y café muy claro en la raíz y la textura de la corteza externa, compacta en el primero, y quebradiza, frágil y de aspecto particularmente elástico en la segunda. En cuanto a las características microscópicas de la raíz encontramos: radios muy expandidos, córtex y felógeno de la peridermis claramente definidos, y fibras de extremos romos, rasgos que no están presentes en el tallo.

Las observaciones realizadas en el presente trabajo nos muestran diferencias con respecto a otras especies estudiadas de Hippocratea en cuanto a la estructura de la madera 
y la corteza del tallo y la raíz, aunque cabe enfatizar el hecho de que la descripción anatómica de la corteza es mucho más detallada que la existente para el resto de las especies de esta familia. Esta información, sin embargo, es insuficiente para definir la circunscripción del género Hippocratea y por lo tanto sugerimos la realización de un estudio comparativo más completo, en donde se analicen otras especies involucradas y que facilite el esclarecimiento de las interrelaciones de la familia Hippocrateaceae.

\section{AGRADECIMIENTOS}

Damos las gracias a la M. en C. Rosa María Fonseca por las sugerencias para llevar a cabo el estudio, así como su apoyo en el campo para la colecta e identificación del material botánico.

Por su parte la primera autora agradece al Instituto de Biología el haber permitido la realización de este trabajo en sus instalaciones, ya que el mismo constituyó su tesis de licenciatura. También y de manera especial expresa reconocimiento al $\mathrm{M}$. en $\mathrm{C}$. Calixto León Gómez por su ayuda en el manejo de técnicas y en la revisión del manuscrito.

\section{LITERATURA CITADA}

Cronquist, A. 1981. An integrated systems of classification of flowering plants. Columbia University Press. Nueva York. 719 pp.

Cutler, D. F., P. J. Rudall, P. E. Gasson y R. M. O. Gale. 1987. Root identification manual of trees and shrubs. Chapman \& Hall. Londres. $317 \mathrm{pp}$.

Chattaway, M. M. 1932. Proposed standards for numerical values used in describing woods. Trop. Woods 29: 20-28.

Dodson C. H. y A. Robyns. 1965. Flora of Panama. Hippocrateaceae. Ann. Miss. Bot. Garden 52(1): 81-98.

Esau, K. 1976. Anatomía vegetal. Ediciones Omega. Barcelona. 779 pp.

IAWA. 1964. Committee on the nomenclature. Multilingual glossary of terms used in wood anatomy. Trop. Woods 107: 1-36.

IAWA. 1989. Committee. IAWA list of microscopic features for hardwood identification. IAWA Bull. n.s. 10(3): 219-332

Johansen, D. A. 1940. Plant microtechnique. 1a. ed. McGraw-Hill. Nueva York. 503 pp.

Junikka, L. 1994. Survey of English macroscopic bark terminology. IAWA Journal 15(1): 3-45.

López, R. 1989. Estudio fitoquímico preliminar de Hippocratea excelsa. Tesis de licenciatura. Facultad de Química, Universidad Nacional Autónoma de México. México, D.F. 89 pp.

Mennega A. M. W. 1972. A survey of the wood anatomy of the New World Hippocrateaceae. In: Ghouse, A. K. M. y M. Yunus (eds.). Research trends in plant anatomy. McGraw-Hill Publishing Company. New Delhi. Pp. 61-72.

Metcalfe, C. R y L. Chalk. 1957. Anatomy of Dicotyledons. Vol. 1. Oxford University Press. Ely Housse, Londres. $1499 \mathrm{pp}$.

Panshin, A. J. y C. De Zeeuw. 1970. Textbook of wood technology. 3a. ed. McGraw-Hill. Nueva York. $705 \mathrm{pp}$.

Patel, R. N. 1965. A comparison of the anatomy of the secondary xylem in roots and stems. Holzforschung 19: 72-79. 
Villa et al.: Estudio Anatómico de Hippocratea excelsa HBK. (Hippocrateaceae)

Roth, I. 1969. Características estructurales de la corteza de árboles tropicales en zonas húmedas. Darwiniana 15: 115-127.

Sass, J. E. 1961. Botanical microtechnique. 3a. ed. lowa State University Press. Ames, lowa. 221 pp.

Smith, A. C. 1940. The American species of Hippocrateaceae. Brittonia 3: 341-555.

Trockenbrodt, M. 1990. Survey and discussion of the terminology used in bark anatomy. IAWA Bull. n.s. 11(2): 141-166.

Aceptado para publicación en abril de 1998. 